\title{
DEVELOPMENT OF CERAMIC FUNCTIONAL LAYERS FOR SOLID OXIDE CELLS
}

\author{
Günter Schiller, Rémi Costa, K. Andreas Friedrich \\ German Aerospace Center (DLR), Institute of Engineering Thermodynamics, Pfaffenwaldring \\ 38-40, 70569 Stuttgart, Germany
}

\section{ABSTRACT}

Ceramic multi-layer systems are the key components of solid oxide cells (SOC) to be used either for power generation or energy storage. Over the last decades continuous improvement in materials, architecture and manufacturing processes have been achieved to improve performance, durability and lifetime. The advanced concept of a metal-supported SOC where the functional ceramic layers are deposited onto a mechanically stable porous metal support is the most advanced approach for mobile application as auxiliary power units (APU) having strict requirements in terms of low volume, limited weight and improved ability for rapid start-up and thermal cycling. The paper provides an overview of the metal-supported cell development at DLR where functional layers are consecutively deposited by plasma spray technology onto a metal substrate. The current status of this development including materials aspects, stack technology and electrochemical performance is reported. When operating temperature is governed mainly by the electrocatalytic properties of the functional electrode materials and thickness of the electrolyte, thin-film electrolyte opens up the opportunity of low temperature operating SOC. Recently, further research efforts have started to develop a metal-supported cell with thin-film electrolyte. Hermetic thin films have been applied through PVD technology resulting in bilayer structured coatings. Recent results of this development are also presented.

\section{INTRODUCTION}

Solid oxide cells for both fuel cell (SOFC) and electrolyzer operation (SOEC) have been developed worldwide for many years because of their promise for highly efficient mutual conversion of chemical and electrical energy and their fuel flexibility. As a consequence, continuous improvement in materials, cell design and manufacturing processing has been achieved in terms of performance and durability, but successful commercialization is still in an initial stage. Different cell types - planar and tubular - with several designs with respect to the supporting component, such as anode-supported cells (ASC), electrolyte-supported cells (ESC) and cathodesupported cells (CSC) have been developed mainly using wet powder processing and sintering techniques as manufacturing technology. In recent years, alternative metal-supported cell designs (MSC) have attracted high interest driven by their low material cost, ruggedness and manufacturing benefits ${ }^{1,2}$. At DLR, an advanced concept of a metal-supported SOC based on thermal spray technology has been developed for mobile application as auxiliary power unit (APU) having strict requirements in terms of low volume, limited weight and improved ability for rapid start-up and thermal cycling. The cell development has been transferred to stack level. In contrast to the ASC, ESC and CSC designs where the mechanical support is a brittle ceramic or cermet, the MSC concept utilizes ceramic layers only as thick as necessary for electrochemical functions. The mechanical support is made from inexpensive and robust porous metal and the electrochemically active layers are applied directly to this metal support. The MSC concept provides significant cost benefits due to reduction of expensive material input and manufacturing advantages. Furthermore, rapid thermal cycling, redox tolerance and other operational advantages make it a very promising candidate for commercialization.

When operating temperature is governed mainly by the electrocatalytic properties of the functional electrode materials and thickness of the electrolyte, thin-film electrolyte opens up the opportunity of low temperature SOC operation. Recently, further research efforts have started at 
DLR to develop an innovative metal-supported cell with thin-film electrolyte applied through PVD technology, using wet powder processing techniques such as tape casting and screen printing for the manufacture of the electrodes. This paper provides an overview of the metalsupported cell development at DLR with both MSC concepts as well as the technical achievements to date.

\section{DEVELOPMENT OF SOC FUNCTIONAL LAYERS BY APPLYING THERMAL SPRAY TECHNOLOGY}

\section{DLR spray concept for SOC}

The principle of the planar DLR concept of a metal-supported SOFC which is based on plasma deposition technology for the manufacture of the entire cell is shown in Fig.1. The mechanical strength of the cell as well as excellent electrical and thermal conductivity is provided by an open porous metal substrate which also serves as a fuel gas distributor. All functional layers of the cell - anode, electrolyte and cathode - are consecutively deposited onto this substrate by a multi-step vacuum plasma spray (VPS) process in a single procedure ${ }^{3}$. The move from a ceramic to a metallic substrate support reduces considerably the problem of crack formation resulting in larger cell size and simplified stack design. A precondition for such a cell and stack design with porous metal support is the availability of a long-term stable and corrosion-resistant material with an adequate thermal expansion behaviour related to the ceramic cell components.

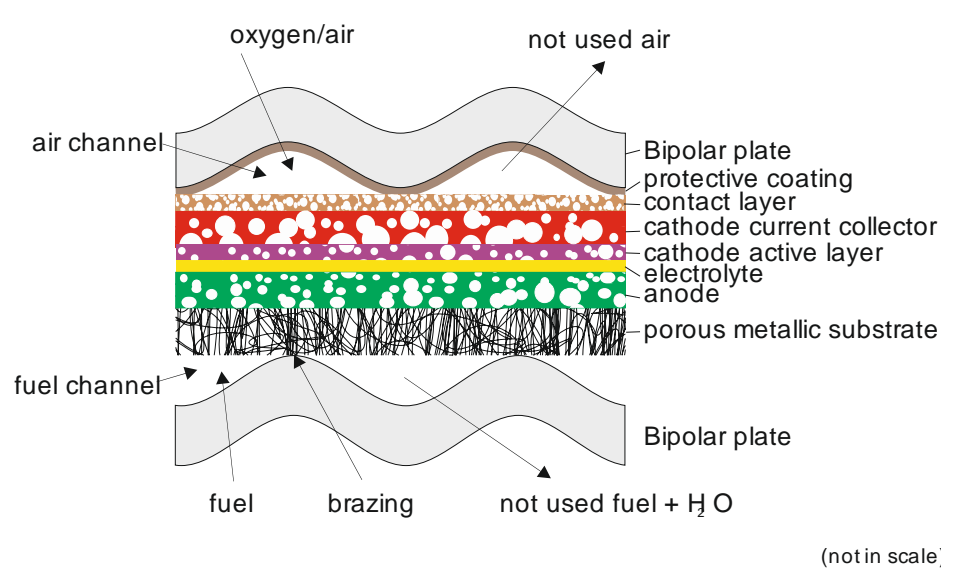

Figure 1. Principle of planar SOC design according to DLR spray concept

In cooperation with an industrial partner a stack design for mobile application has been developed on the basis of plasma sprayed cells and ferritic steel interconnects. This design is based on thin stamped metal sheets which are laser welded to form a metallic cassette arrangement. The integration of the porous substrate is done by welding and brazing of the substrate into the cassette. Cell layers are then plasma- sprayed on the porous substrate-interconnector unit. During this coating process the gas tight electrolyte layer is also sprayed over the weld seam which connects the substrate and the frame. With this process step a seal on the side of the cell is established which is more reliable than the glass seal alone. The brazing and welding of the substrate also provides an excellent electrical contact to the anode side. The concept with integrated metal substrate is shown in Fig. 2. 

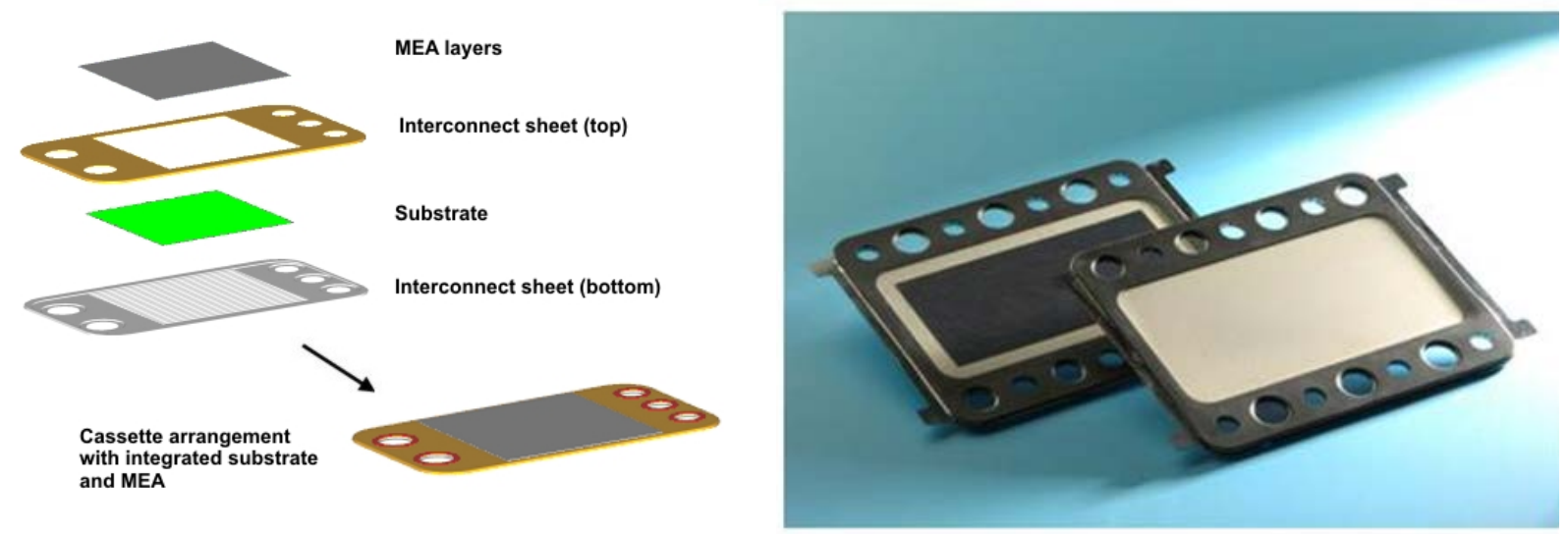

Figure 2. Cassette arrangement with plasma sprayed cells for stack assembly

\section{MANUFACTURING OF FUNCTIONAL SOC LAYERS BY PLASMA SPRAY DEPOSITION}

The metal support on which the functional electrode and electrolyte layers are deposited is a core component of plasma-sprayed cells. It has to exhibit a sufficient open porosity of at least $40 \%$, an adapted coefficient of thermal expansion to that of the electrolyte to enable rapid thermal cycling, a low oxidation rate and low cost. In early investigation at DLR ferritic stainless steel substrates with high chromium (> 20 wt.-\%) and low manganese content ( $0.02-0.05$ wt.-\%) were identified to be well suited for this application. In particular corrosion stability was found to be adequate. For this reason a powder metallurgically (P/M) manufactured porous ODS (oxide dispersive strengthened) FeCr-alloy which forms a protective oxide scale during cell operation developed by Plansee SE, Austria, is the preferred choice to be used as metal support. Figure 3 shows a typical morphology of the Plansee manufactured substrates illustrating the porous structure characteristics. The pore size distribution is in the range of about 5 - $50 \mu \mathrm{m}$ and the porosity could be determined to approx. 48 vol.\% by means the quantitative image analysis (QPA) measurement technique.

Furthermore, a diffusion barrier layer with a thickness of 10-15 $\mu \mathrm{m}$ consisting of LSCr and deposited by plasma spraying has been introduced to prevent the diffusion of iron into the SOFC anode and the diffusion of nickel into the substrate ${ }^{4}$.
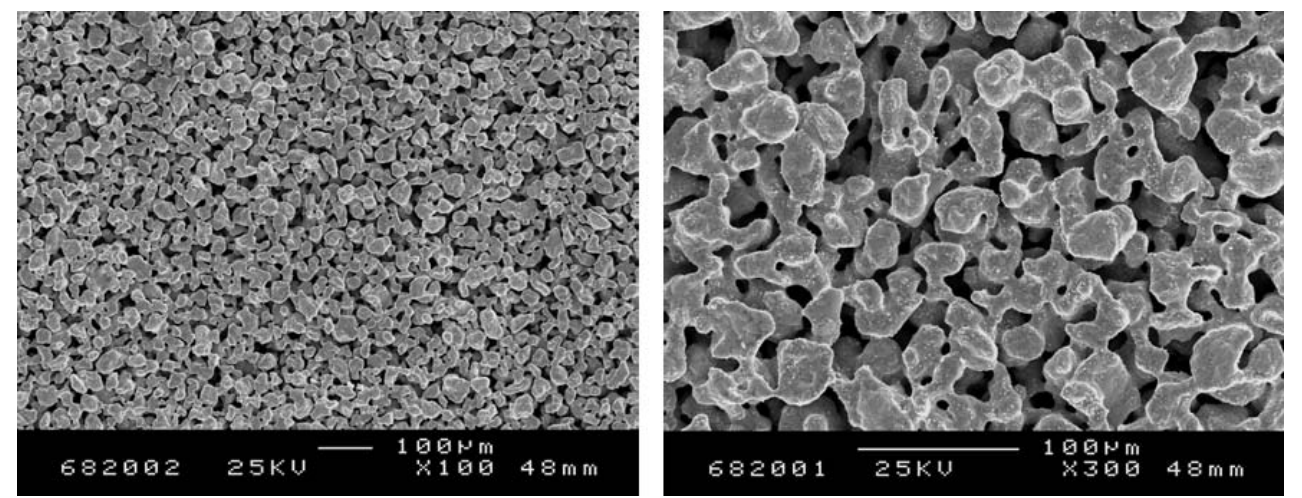

Figure 3. SEM image of typical morphology of the metallic PM Fe-26Cr-(Mo,Ti,Mn, $\left.\mathrm{Y}_{2} \mathrm{O}_{3}\right)$ porous substrate from Plansee 
For the deposition of the ceramic layers special plasma spraying equipment has been developed and used at DLR. Fast plasma jet and spray material velocities which are needed for dense electrolyte layers were realized by using a direct current (DC) torch with Laval-like contoured anodes. The torch was integrated into a low pressure chamber ${ }^{5}$. To fabricate the electrode layers a three-cathode plasma gun TriplexPro 200 (Oerlikon Metco, Switzerland) was applied under atmospheric conditions (APS). Besides standard-sized powder particles (20-60 $\mu \mathrm{m})$ also suspensions with sub-micron particles were injected. An in-house developed injection system for suspension plasma spraying (SPS) and solution precursor plasma spraying (SPPS) was adapted to get denser electrolyte coatings as well as electrode coatings with higher triple phase boundaries (TPB).

Although there has been extensive study on alternative solid electrolyte materials, e.g. scandium doped zirconia (ScSZ), gadolinia doped ceria (GDC), lanthanum gallate-based perovskite (LSGM) ${ }^{6}$, the most commonly used electrolyte material for SOFC is still $8 \mathrm{~mol} \%$ yttriastabilized zirconia (8YSZ) due to its high stability and low electronic conductivity at elevated temperatures ${ }^{7}$. However to reduce the resistivity related to oxygen ion diffusion in $8 Y S Z$, either higher operating temperature or thinner electrolyte layers are options. The production of thin electrolyte layers for operating temperatures below $800{ }^{\circ} \mathrm{C}$ is a major challenge for plasmasprayed SOFC. Using a D-optimal design of experiments (DOE), influence of different 8YSZ feedstock powders and plasma spray parameters were investigated on deposition efficiency, gastightness and electrochemical behaviour of vacuum plasma sprayed (VPS) electrolytes ${ }^{8}$. It was found that the influence of particle velocity on open porosity of the deposit is four times higher than the particle temperature. Owing to this finding thickness and area-specific leak rate could be reduced from $65 \mu \mathrm{m}$ to $35 \mu \mathrm{m}$ and from 15.2 to $1.7 \mathrm{~Pa} \mathrm{~m} / \mathrm{s}$, respectively, which consequently resulted in lower ohmic resistance and higher open circuit voltage (OCV) for cells. Despite this tremendous progress in plasma spraying of electrolytes further improvement is needed. For instance, the ionic conductivity of as-sprayed layers is threefold lower than that of sintered ones which is attributed to the splat boundaries which hinder ion diffusion across the deposit ${ }^{9}$. In order to enhance ionic conductivity as well as gas-tightness of the electrolyte layer, experiments have been started with suspension plasma spraying (SPS) using nanostructured powders.

The requirements of the anode to be fulfilled are a high electronic conductivity to minimize electric losses and to supply electrons and to permit access of the fuel due to its high porosity. The electrochemical performance of an anode layer is mainly governed by active reaction sites (triple phase boundary: TPB) where oxide ions from the electrolyte, fuel gas and electrode are in close contact. Usually, a cermet of $\mathrm{Ni}$ and YSZ is used as anode material. With plasma spraying $\mathrm{NiO}$ and YSZ powder feedstock is used; NiO is then reduced during operation by hydrogen to nickel. A further increase of the anode porosity to around $25-30$ vol.\% is obtained during the reduction process. An optimal ratio between 8YSZ and nickel after reduction is considered to be around 70/30 vol.\%. Another challenge for plasma-sprayed SOC anodes is to achieve a surface roughness as low as possible. The smoother the anode the thinner a gas-tight plasma sprayed electrolyte can be deposited on top of it. Generally, the roughness in plasma spraying is limited by the splat characteristics and, thus, by the powder particle size.

As cathode material mainly perovskite-type oxides such as $\mathrm{La}_{0.6} \mathrm{Sr}_{0.4} \mathrm{MnO}_{3}$ (LSM) or $\mathrm{La}_{0.6} \mathrm{Sr}_{0.4} \mathrm{Co}_{0.2} \mathrm{Fe}_{0.8} \mathrm{O}_{3}$ (LSCF) are used ${ }^{10}$. Compared to the anode the porosity of the cathode is limited with conventional plasma spraying to less than $20 \%$ due to the lack of the "pore forming" reduction process taking place at the cathode. Higher cathode porosity can be obtained by developing mixed nano-micro-structured cathodes. The nanoparticles offer a high effective surface 
area, however, nanoparticles tend to agglomerate and sinter at cell operating temperatures. Micrometer-sized particles were therefore introduced to impede sintering of the nanoparticles. A 20 to $80 \mathrm{wt}$ \% ratio of nanometer- to micrometer-sized particles was adapted in which the the nanometer-sized particles were in the range of 60 to $90 \mathrm{~nm}$ and micometer-sized particles were 0.8 to $2 \mu \mathrm{m}$. The particles were agglomerated to a size of 5-45 $\mu \mathrm{m}$ using spray-drying prior to plasma spraying. Special care is needed during plasma spraying to avoid decomposition of these materials at high temperature and reducing atmosphere. A porosity beyond $20 \%$ was achieved in this way. A metallographic cross section of an entirely plasma sprayed cell deposited onto a porous metallic substrate is shown in Fig. 4.

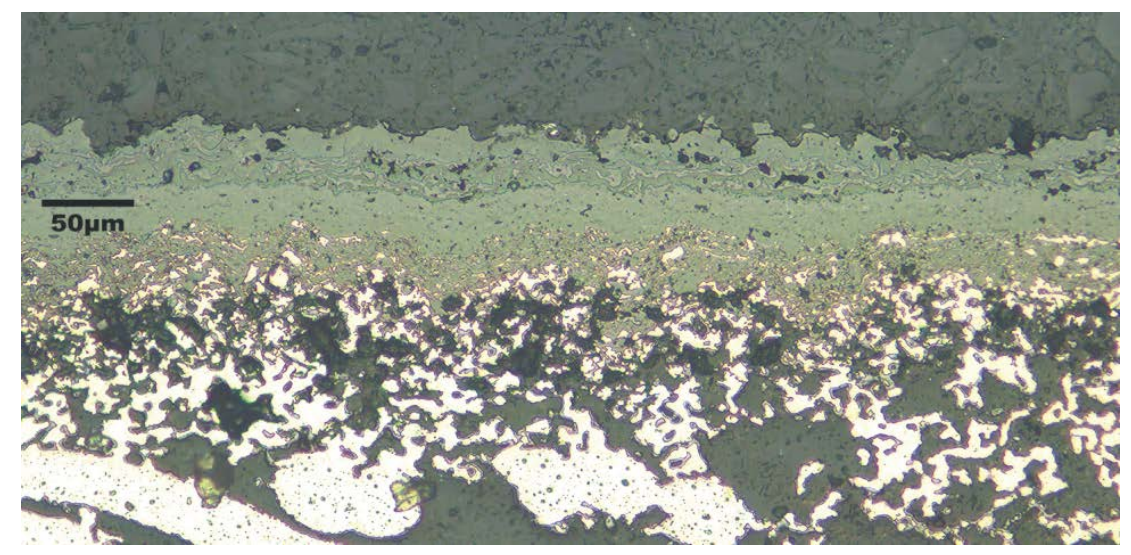

Figure 4. Metallographic cross-section of an entirely plasma sprayed cell on metallic support

Besides the manufacture of active layers as described, plasma sprayed coatings can also be applied for corrosion protection, for insolation between cell components and for sealing in SOC stacks which has been described in more detail in ${ }^{4,11}$.

\section{ELECTROCHEMICAL PERFORMANCE OF METAL SUPPORTED SOC}

Electrochemical test results of small cells with an area of $12.5 \mathrm{~cm}^{2}$ using simulated reformate gas as fuel $\left(\mathrm{H}_{2} / \mathrm{N}_{2} / \mathrm{H}_{2} \mathrm{O}: 48.5 / 48.5 / 3.0\right.$ vol.\%) and air as oxidizing gas showed at an operating temperature of $800{ }^{\circ} \mathrm{C}$ a power density of up to $800 \mathrm{~mW} / \mathrm{cm}^{2}$. Up-scaling to $85 \mathrm{~cm}^{2}$ and $100 \mathrm{~cm}^{2}$ effective area cells was accomplished and the cells revealed a power density of 400 $\mathrm{mW} / \mathrm{cm}^{2}$ at a fuel utilization of $32 \%$ at $800{ }^{\circ} \mathrm{C}$. The test of short-stacks and stacks up to 10 cells $(250 \mathrm{~W})$ gave a power density $>300 \mathrm{~mW} / \mathrm{cm}^{2}{ }^{2}$. Further improvement in stack power is needed and can be achieved with improved stack design to decrease enhanced ohmic losses.

Plasma-sprayed cells show a superior resistance to strong temperature and redox cycling tests compared to ASC cells. Strong anode reduction during SOFC operation was conducted by switching off the fuel gas abruptly and purging with nitrogen for $5 \mathrm{~min}$. to remove residual hydrogen. Subsequently, $50 \mathrm{ml} / \mathrm{min}$ pure oxygen was fed for 1 hour to oxidize the nickel in the anode completely. 20 of such redox cycles together with 15 thermal cycles could be performed with a 10-cell stack. The degradation rate after 20 cycles was $9.1 \%$ due to micro-cracks caused by volume changes during redox cycling. A long-term test of a 4-cell stack over 5000 h showed a degradation rate of $10.7 \% / 1000 \mathrm{~h}(4 \% / 1000 \mathrm{~h}$ during the first $2500 \mathrm{~h})$ which is a promising value due to the fact that no protective coatings had been used. For industrial applications the degradation rate must be further reduced ${ }^{2}$. 
The metal supported cells were also tested in electrolysis mode. During electrolysis operation at an operating temperature of $850{ }^{\circ} \mathrm{C}$ a cell voltage of $1.28 \mathrm{~V}$ was achieved at a current density of $-1.0 \mathrm{~A} \mathrm{~cm}^{-2}$; at $800{ }^{\circ} \mathrm{C}$ the cell voltage was $1.40 \mathrm{~V}$ at the same operating conditions. The impedance spectra revealed a significantly enhanced polarization resistance during electrolysis operation compared to fuel cell operation which was mainly attributed to the hydrogen electrode. During a long-term test run of a single cell over 2000 hours a degradation rate of 3.2\% per 1000 hours was observed for operation with steam content of $43 \%$ at $800{ }^{\circ} \mathrm{C}$ and a current density of $-0.3 \mathrm{Acm}^{-2} 12$.

\section{BEYOND THE PLASMA SPRAY CONCEPT}

Though showing improved mechanical properties, the developed MSC concept still face critical challenges correlated with the nature of the structural and electro-catalytic materials employed so far. Indeed, considering long term application - 5000 hours and more - the porous ferritic stainless steel substrate suffer irreversible corrosion at operating conditions which makes the MSC concept less attractive for stationary applications. With the target to operate the SOFC system with syngas, a major drawback remains the sensitivity of traditional anodes regarding sulfur poisoning. This issue is encountered in all present cell designs, if the anode is based on the traditional cermet system, namely nickel/yttria-stabilized zirconia, which moreover suffer irreversible degradation over redox cycles ${ }^{1}$. Among alternative anodic electro-catalysts, compounds based on strontium titanate have shown high potential ${ }^{13}$ and demonstrated capabilities to withstand redox cycles ${ }^{14}$.

Aiming at replacing nickel, as electro-catalyst from the anode, while increasing lifetime of the metal supported cell, a new cell design has been recently conceived and is being developed in the frame of an European funded project EVOLVE (Grant Agreement 303429). The innovation of the EVOLVE cell concept remains in its anode compartment without having nickel as structural component (Figure 5). The anode compartment is based on a metal alloy forming a protective alumina layer enhancing stability during re-oxidation cycles and an electronic conducting perovskite for the current collection. This combination is expected to create a cermet type hybrid current collector, with a mechanical stability similar to the MSCs and a microstructure similar with the one from anodic substrate of ASCs.

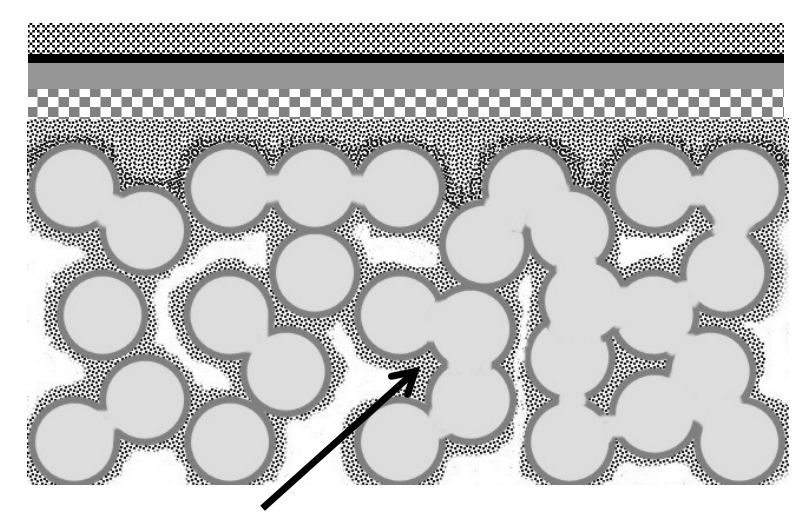

Hybrid substrate

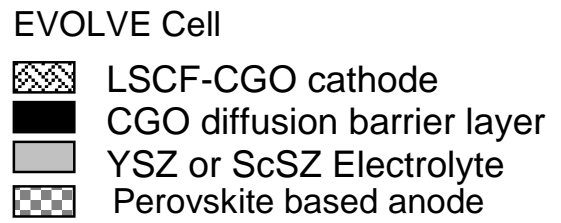

Perovskite based anode

Figure 5. Schematic of the EVOLVE type cell 
In this concept, a NiCrAl foam (Alantum GmbH, Germany) with open pore size of about $450 \mu \mathrm{m}$ (Figure 6.a) is used as metallic substrate to enhance the stability of the cell. A perovskite namely $\mathrm{La}_{0.1} \mathrm{Sr}_{0.9} \mathrm{TiO}_{3-\alpha}$ - LST (CerPoTech, Norway) - was used for the current collection when combined with the metal foam and as anodic electro-catalyst for anode in combination with $\mathrm{Ce}_{0.9} \mathrm{Gd}_{0.1} \mathrm{O}_{2-\alpha}$ - GDC (Treibacher, Austria) - in a composite, as replacement of the Ni - YSZ cermet. Coarsened LST ceramic was infiltrated into the NiCrAl foam further and fired at 1000 ${ }^{\circ} \mathrm{C}$ (Figure 6(b)) allowing a pore size reduction down to the submicronic range making a compromise between the requirement for good gas permeation while allowing the deposition of a thin functional anode layer without macroscopic defects ${ }^{15}$. The NiCrAl metal foam as the structural framework ensured the mechanical strength of the substrates. The functional LST-GDC anode layer is then coated on top, using a fine LST powder in order to maximize the solid-gas exchange surface area which seems to control the performance of perovskite based anode towards hydrogen oxidation though the exact mechanism is not yet fully elucidated ${ }^{16}$. The use of a fine powder in the functional anode layer allows further reducing the pore size down to less than $100 \mathrm{~nm}$ at the top surface, crucial for the manufacturing of a thin electrolyte layer (Figure 6(c)). YSZ layer is coated on top.
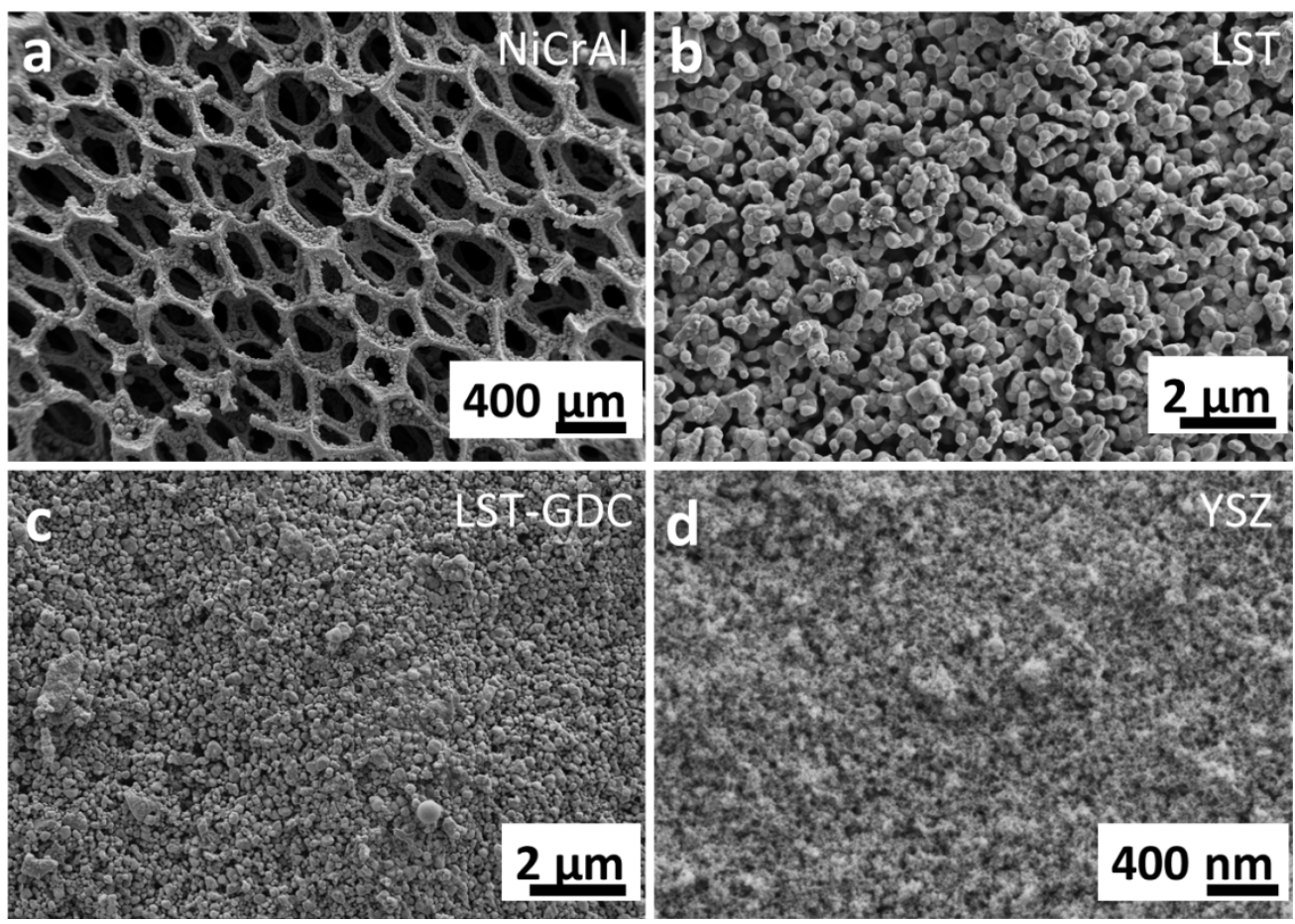

Figure 6. SEM of NiCrAl foam and NiCrAl-LST substrates: (a) top view of NiCrAl foam, (b) top view of NiCrAl foam fired with impregnated LST ceramic, (c) top view of the anode functional layer LST-GDC, (d) top view of the YSZ layer after dip coating (non sintered) ${ }^{15}$,

It is observed in Figure 7 (a) and (c) that the YSZ layer and an EB-PVD GDC layer have been homogeneously deposited on top of the LST-GDC anode layer. The thickness of the calcined LST-GDC anode layer was about $20 \mu \mathrm{m}$ whereas total thickness of the crack-free YSZ and GDC double layer was approximately $3 \mu \mathrm{m}$. The top view of fine structured GDC layer shown in Figure 7(b) reveals that the GDC layer is dense and the grain size is below $200 \mathrm{~nm}$. The elemental mapping for the SEM in Figure 7(c) is shown in Figure 7(d), indicating at the LST- 
GDC/YSZ/GDC interfaces no element interdiffusion between the YSZ and GDC phases. Due to the homogeneous YSZ layer and the dense GDC layer, the half cells realized excellent gastightness with air leakage rate as low as 0.4 Pa.m.s ${ }^{-1}$ despite the extremely thin electrolyte. This low leak rate, combined with the thin film electrolyte is expected both to increase the OCV value of such a cell, while reducing ohmic drop linked to the thickness of the electrolyte when compared to the plasma sprayed ones. Work is ongoing to deposit the cathode and perform electrochemical testing of the cells and the results will be published in the future.



Figure 7. SEM of half cells with dip-coated YSZ layer and EB-PVD GDC layer: (a) overview cross section, (b) top view of GDC layer, (c) cross section at LST-GDC/YSZ/GDC interfaces, (d) elemental mapping at LST-GDC/YSZ/GDC interfaces ${ }^{15}$.

\section{CONCLUSION}

Metal-Supported-SOCs represent a promising concept to overcome the commercialization hurdles for SOFC and SOEC systems. The plasma-sprayed cell concept was successfully scaled up to $84 \mathrm{~cm}^{2}$ and demonstrated suitable power densities and durability. Also, innovative concepts with thin-layer electrolyte open new paths to enhanced performance and system cost reduction.

\section{ACKNOWLEDGEMENTS}

Dr. F. Han (DLR), and Dr. R. Semerad (Ceraco GmbH) are greatly acknowledged for providing samples with thin film electrolytes. A part of this work was funded by the European Union's Seventh Framework Programme (FP7/2007-2013) for the Fuel Cells and Hydrogen Joint Technology Initiative under grant agreement $n^{\circ} 303429$. 


\section{REFERENCES}

${ }^{1}$ M.C. Tucker; "Progress in metal-supported solid oxide fuel cells”, J. Power Sources, 195, pp. 4570-4582, 2010

${ }^{2}$ D. Soysal, J. Arnold, P. Szabo, R. Henne, S.A. Ansar, "Thermal plasma spraying applied on solid oxide fuel cells”, J. Therm. Spray Technol., 22(5), pp. 588-598, 2013

${ }^{3}$ G. Schiller, R. Henne, M. Lang, M. Müller, “Development of solid oxide fuel cells by applying DC and RF plasma deposition technologies”, Fuel Cells, 4(1-2) , pp. 56-61 , 2004

${ }^{4}$ T. Franco, R. Ruckdäschel, M. Lang, G. Schiller, P. Szabo, “Diffusion and protecting barrier layers in a substrate-supported SOFC concept”, Proceedings $7^{\text {th }}$ European Solid Oxide Fuel Cell Forum, 3-7 July 2006, Lucerne, Switzerland, P0802, 2006

${ }^{5}$ R. Henne, "Solid oxide fuel cells: A challenge for plasma deposition processes", J. Therm. Spray Technol., 16(3), pp. 381-403, 2007

${ }^{6}$ L. Jia, C. Dossou-Yovo, C. Gahlert, F. Gitzhofer, "Induction plasma spraying of samarium doped ceria as electrolyte for solid oxide fuel cells”, Thermal Spray 2004: Advances in Technology and Application, ASM International, 10-12 May, Osaka, Japan, pp. 85-89

${ }^{7}$ D. Stolten, Hydrogen and Fuel Cells, Wiley-VCH Verlag, Weinheim, 2010

${ }^{8}$ S.A. Ansar, Z. Ilhan, J. Arnold, "Plasma sprayed metal supported SOFCs having enhanced performance and durability”, Int. Thermal Spray Conference, 4-6 May 2009, Las Vegas, USA

${ }^{9}$ C. Christenn, S.A. Ansar, "Sprayed and constrained-sintered zirconia-based electrolytes", Thermal Spray 2009: Expanding Thermal Spray Performance to New Markets and Applications, ASM International, pp. 131-135, 2009

${ }^{10}$ Y. Shen, V.A.B. Almeida, F. Gitzhofer, "Preparation of nanocomposite GDC/LSCF cathode material for IT-SOFC by induction plasma spraying”, J. Therm. Spray Technol. 20(1-2), pp. 145153, 2011

${ }^{11}$ J. Arnold, S.A. Ansar, U. Maier, R. Henne, "Insulating and sealing of SOFC devices by plasma sprayed ceramic layers”, Int. Thermal Spray Conference, Thermal Spray 2008: Crossing Borders (DVS-ASM), 2-4 June 2008, Maastricht, Netherlands

${ }^{12}$ G. Schiller, A. Ansar, M. Lang, O. Patz, "High temperature water electrolysis using metal supported solid oxide electrolyzer cells (SOEC)”, J. Appl. Electrochem., 39, pp. 293-301, 2009

${ }^{13}$ M.C. Verbraeken, T. Ramos, K. Agersted, Q. Ma, C.D. Savaniu, B.R. Sudireddy, J.T.S. Irvine, P. Holtappels, F. Tietz, "Modified strontium titanates: from defect chemistry to SOFC anodes", RSC adv., 5, pp. 1168-1180, 2015

${ }^{14}$ Q. L. Ma, F. Tietz, A. Leonide, E. Ivers-Tiffee, “Anode-supported planar SOFC with high performance and redox stability”, Electrochemistry Communications, 12, pp. 1326-1328, 2010

${ }^{15}$ F. Han, R. Semerad, R. Costa, "Development of metal foam supported SOFCs”, Proceedings of the $11^{\text {th }}$ European SOFC \& SOE Forum 2014, 1-4 July 2014, Lucerne, Switzerland, A1506

${ }^{16}$ V. Yurkiv, G. Constantin, A. Hornes, A. Gondolini, E. Mercadelli, A. Sanson, L. Dessemond, R. Costa, J. Power Sources, 287, pp. 58-67, 2015 